Wei-Wu Pang MD, Da-Peng Chang $\mathrm{MD}$, Ching-Hsiung Lin $\mathrm{MD}$, Min-Ho Huang $\mathrm{MD}^{\star}$

\title{
Negative pressure pul- monary oedema induced by direct suctioning of endotracheal tube adapter
}

Purpose: Negative pressure pulmonary oedema (NPPE) is a well-recognized but rare complication secondary to upper airway obstruction such as laryngeal spasm during emergence from general anaesthesia. Cauterization of the second and third thoracic sympathetic ganglia is a treatment for hyperhidrosis of the hands. We report a case of NPPE induced by direct suctioning of the endotracheal tube adapter during thoracic sympathetic ganglionectomy without recognized upper airway obstruction.

Clinical features: A 19-yr-old otherwise healthy, non-smoking man was scheduled for elective bilateral chest endoscopic ablation of the second and third thoracic sympathetic ganglion for hyperhidrosis of the hands under general anaesthesia. To view and cauterize the ganglion with the endoscope, the surgeon requested cessation of positive pressure ventilation. As the surgeon could not satisfactorily visualize the target ganglia, he requested brief application of wall suction via the ETT tube adapter. A pressure of $-100 \mathrm{mmHg}$ was generated which lasted for three to four seconds. The goal was to reduce further the lung volume by increasing the pneumothorax produced by the endoscope. The patient developed negative pressure pulmonary oedema without upper airway obstruction.

Conclusion: This case demonstrated that intrathoracic negative pressure generated by direct ETT adapter suctioning may produce pulmonary oedema similar to that induced by laryngeal spasm during the emergence of general anaesthesia.

Objectif : L'œdème pulmonaire à pression négative (EPPN) est une complication rare, mais bien connue, secondaire à l'obstruction des voies aériennes supérieures comme le spasme laryngé pendant la récupération de l'anesthésie générale. La cautérisation des deuxième et troisième ganglions sympathiques dorsaux constitue un traitement pour l'hyperhidrose des mains. Nous rapportons ici un cas de EPPN induit par aspiration directe à travers l'adaptateur du tube endotrachéal (TET), pendant la ganglionectomie sympathique dorsale sans obstruction reconnue des voies aériennes supérieures.

Aspects cliniques : Un homme de 19 ans, non fumeur, par ailleurs en bonne santé, devait subir sous anesthésie générale l'ablation endoscopique élective des deuxième et troisième ganglions sympathiques dorsaux bilatéraux pour enrayer l'hyperhidrose des mains. Dans le but de visualiser et de cautériser le ganglion avec l'endoscope, le chirurgien a demandé d'arrêter la ventilation à pression positive. Cette mesure étant insatisfaisante, il a demandé une brève application de l'aspiration par l'adaptateur du TET. Une pression de $-100 \mathrm{mmHg}$ a été produite et a duré de trois à quatre secondes. Le but était de réduire davantage le volume pulmonaire en accroissant le pneumothorax produit par l'endoscope. Le patient a subi un œedème pulmonaire à pression négative, sans obstruction des voies aériennes supérieures.

Conclusion : Ce cas démontre que la pression intrathoracique négative générée par l'aspiration directe à travers l'adaptateur du TET peut produire un œè̀me pulmonaire similaire à celui qui est induit par le spasme laryngé pendant la récupération de l'anesthésie générale.

From the Department of Anesthesia and Surgery, "Show-Chwan Memorial Hospital, 542 Chung-Shang Road, Section 1, Changhua, Taiwan, R.O.C.

Address correspondence to: Dr Wei-Wu Pang, Department of Anesthesia, Show-Chwan Memorial Hospital, Chung-Shang Rond, Section 1, Changhua, Taiwan, R.O.C. Phone: 886-4-7256166, Ext. 3028; Fax: 886-4-7227116

Accepted for publication May 24, 1998. 


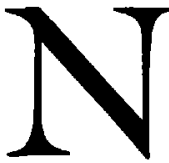

EGATIVE pressure pulmonary oedema (NPPE) is a well-recognized but rare complication of upper airway obstructions such as laryngospasm, ${ }^{1}$ croup, ${ }^{2}$ epiglottitis, ${ }^{2}$ traumatic strangulation, ${ }^{3}$ foreign material ${ }^{4}$ and tumour ${ }^{5}$ etc. However NPPE caused by direct application of suction to an endotracheal tube (ETT) has never been reported. We present a patient who developed NPPE during direct application of suction to the ETT adapter during bilateral chest endoscopic ablation of the second and third thoracic sympathetic ganglia for hyperhidrosis, a common disease in Taiwan.

\section{Case report}

A 19-yr-old otherwise healthy, non-smoking man was scheduled for elective sympathetic ganglionectomy for hyperhidrosis of the hands. There was no previous medical or surgical history. He was $165 \mathrm{~cm}$ tall and weighed $65 \mathrm{~kg}$. He was afebrile and his vital signs were normal. Except for excessive sweating of the hands, preoperative physical examination was normal. The routine laboratory values were all normal.

He had been fasting since mid-night. No pre-medication was given. After placement of standard monitors including end-tidal $\mathrm{CO}_{2}$ and pulse oximeter, three minutes of pre-oxygenation via a face mask was followed by $150 \mathrm{mg}$ propofol and $80 \mathrm{mg}$ succinylcholine via a 20 gauge intravenous cannula on the left hand. The trachea was intubated with a $7.5-\mathrm{mm}$ cuffed ETT. Anaesthesia was maintained with $100 \mu \mathrm{g}$ fentanyl and propofol infused at $10 \mathrm{mg} \cdot \mathrm{min}^{-1}$. The lungs were ventilated with a nitrous oxide/oxygen mixture of 1:1. No muscle relaxant was used.

A $1 \mathrm{~cm}$ skin incision was made via an axillary approach and the pleural cavity was entered with an endoscope by the surgeon. To view and cauterize the 2nd and 3rd thoracic sympathetic ganglia $\left(T_{2,3}\right)$ the surgeon usually requested the anaesthetist to cease positive pressure ventilation. As the surgeon could not satisfactorily visualize the $T_{2,3}$ ganglion, he continued to keep the lung still and requested transient application of suction to the ETT tube adapter. A negative pressure of $100 \mathrm{mmHg}$ was quickly generated and lasted for three to four seconds. The goal was to shrink the lungs further by slightly increasing the pneumothorax produced by the endoscope on the operative side. When the ganglionectomy had been completed, the lungs were manually hyperventilated four-six times. In order to prevent iatrogenic pneumothorax, the surgeon removed the endoscope and closed the skin while the lungs were kept in inspiration at $30 \mathrm{~cm} \mathrm{H}_{2} \mathrm{O}$ pressure for six to eight seconds. The other side was treated in the same fashion. It took 10 min for each side operative procedure. The duration of lung collapse for the cauterization of $\mathrm{T}_{2,3}$ ganglion was less than three minutes. At no time did $\mathrm{SpO}_{2}$ decrease to $<95 \%$ or $\mathrm{P}_{\mathrm{ET}} \mathrm{CO}_{2}$ increase to $>40 \mathrm{mmHg}$. There were no ECG or vital sign changes. This technique had been used by this particular surgeon for several years and was found useful in visualizing the target ganglia. At the end of anaesthesia the patient was breathing spontaneously and awake enough to open his eyes on command, the trachea was extubated without difficulty. There was no laryngospasm, upper airway obstruction or pronounced thoracic retraction noticed. A total of $100 \mathrm{ml}$ Ringer's lactate was infused. Fifteen minutes after the final application of negative pressure and eight minutes after extubation the patient was brought to the recovery room.

Five minutes later, he was still sleepy but able to follow verbal commands. Shallow tidal volume breathing gradually developed with decreased $\mathrm{SpO}_{2}$. On auscultation, the breathe sounds were markedly decreased bilaterally on spontaneous respiration. No change in consciousness (drowsy but easily roused) was recognized. The lungs were ventilated immediately with bag/mask and oxygen without difficulty; chest excursion was free and there were no signs of upper airway obstruction. Although the breath sounds were clear on bag ventilation, the $\mathrm{SpO}_{2}$ did not increase to $>92$ $\mathrm{mmHg}$. Arterial blood gas (ABG) analysis showed $\mathrm{pH}$ 7.26, $\mathrm{PO}_{2} 62.2 \mathrm{mmHg}$ and $\mathrm{PCO}_{2} 49.8 \mathrm{mmHg}$ with $\mathrm{FiO}_{2}$ of 1.0. The trachea was immediately re-intubated without medication. There were no unusual findings noticed during the laryngoscopy. However, pink, frothy pulmonary secretions were suctioned from the trachea after intubation. A CXR showed bilateral centralized interstitial infiltrates and a normal heart size. A 12-lead ECG was normal. Mechanical ventilatory support with $10 \mathrm{~cm} \mathrm{H}_{2} \mathrm{O}$ of PEEP and intermittent tracheal suction was started. The amount of suction decreased gradually. Chest X-ray $12 \mathrm{hr}$ later revealed diminished infiltrates and $A B G$ analysis breathing room air via a $T$-piece was normal. The trachea was subsequently extubated and the patient was discharged home without sequelae.

\section{Discussion}

Intra-pulmonary negative pressure generated by respiration against a closed upper airway has been implicated as a major precipitating factor for NPPE. ${ }^{6}$ Laryngospasm is one of the most common causes of post-anaesthetic upper airway obstruction ${ }^{6,7}$ In this case there was no evidence of upper airway obstruction such as laryngospasm, falling tongue, etc., following extubation, nor difficult ventilation during bag/mask resuscitation. The patient developed hypoventilation and 
cyanosis with a patent airway. The airway was normal by laryngoscopy during re-intubation. The only factor temporally related to the pulmonary oedema was the negative pressure secondary to the direct active suction of the ETT tube adapter. The pulmonary oedema could have been caused by two suction challenges since no double lumen endobronchial tube was used to limit the negative pressure exposure only to the operated lung.

Starling"s law describe the net fluid filtration at any point within the pulmonary vascular bed as expressed in the equation: 6,8

$$
\mathrm{Q}=\mathrm{kA}[(\mathrm{Pc}-\mathrm{Pi})+\delta(\pi \mathrm{i}-\pi \mathrm{c})]
$$

Where $Q=$ fluid filtration, $k=$ capillary filtration coefficient (conductivity of water), $\mathrm{A}=$ the area of the capillary membrane, $\mathrm{Pc}=$ capillary hydrostatic pressure, $\mathrm{Pi}=$ interstitial hydrostatic pressure, $\delta=$ reflection coefficient for albumen, $\pi \mathrm{i}=$ interstitial colloid oncotic pressure, and $\pi c=$ capillary colloid oncotic pressure. Disruption of this balance by intrathoracic negative pressure is, theoretically, the major cause of transudation of fluid/blood from the capillaries to the interstitium. ${ }^{6}$ In this case report, the disruption of the equilibrium originated from the intrathoracic negative pressure secondary to suctioning of the ETT adapter. Multi-factorial pathogenesis of NPPE has been described by Lang et al. ${ }^{6}$ Intra-thoracic negative pressure increases venous return to the right heart and decreases the output of the left ventricle. This results in an increase of pulmonary blood volume and micro-vascular pressure, followed by pooling of blood in the lungs, loss of capillary integrity, redistribution of blood volume to the pulmonary system, decrease in the functional residue volume, hypoxia and myocardial depression. ${ }^{6}$

Chest ganglionectomy is an effective treatment for hyperhidrosis. It is a very short procedure for a relatively common disease in this subtropical country. Some surgeons use direct transient ETT adapter suctioning to expedite visualizing the $T_{2,3}$. The arm receives sympathetic fibres from $T_{1-6}$, the lung receives fibres from $T_{2}$. 6 , and the heart receives fibres from $\mathrm{T}_{1-5} .{ }^{9}$ Although ganglionectomy improves the hyperhidrosis, it can also theoretically interrupt the $\mathrm{T}_{2,3}$ sympathetic flow to the heart and the lungs. The effect of $\mathrm{T}_{2,3}$ ganglionectomy on these organs is unclear although we have never seen adverse effects on the heart and lungs. This may partly be explained in that the lesions caused by electric cauterization are very localized. The remaining autonomic structures are still intact and the intact part of the sympathetic system may maintain their normal function on heart and lungs. ${ }^{10}$ However, we should never neglect the potential for complications in this procedure.
Several criteria exclude aspiration. First, The suctioned fluid via the ETT was pink and frothy without gastric secretion, sputum or food materials. Second, NPO for eight hours was strictly applied and there was no vomiting or regurgitation. Third, the initial effect of desaturation was dramatic, with a very rapid resolution, a clinical pattern very different from pulmonary aspiration. Fourth, CXR showed a centralized diffuse pattern of interstitial infiltrates consistent with pulmonary oedema but not aspiration. A total intravenous infusion of $100 \mathrm{ml}$ Ringer's lactate and no history of heart disease excluded the fluid overload or cardiogenic pulmonary oedema.

Re-expansion pulmonary oedema (REPE) is a different clinical entity ${ }^{11}$ and usually occurs after prolonged lung collapse, mostly from pleural effusion or pneumothorax. With rapid re-expansion of the collapsed area of alveoli, the previous atelectatic parenchyma undergoes re-perfusion and ventilation. These events may be followed by a form of high-permeability pulmonary oedema that is confined to the side of the reexpanded lung. ${ }^{11,12}$ In our case, the REPE could be excluded because the time course of the collapse was too brief and the pulmonary oedema was bilateral. The sudden onset and rapid resolution were also not consistent with the clinical picture of REPE. ${ }^{11}$

The treatment for NPPE has been very well described. ${ }^{6,13}$ Careful observation is required for several hours after an episode of upper airway obstruction from any causes. ${ }^{6,7}$ The keys to management are early recognition of NPPE and provision of adequate arterial oxygenation by maintenance of the airway. Re-intubation and mechanical ventilation with PEEP is necessary for more serious NPPE. It is possible to use nasal CPAP or BIPAP for transient and mild NPPE which is a non-invasive alternative to re-intubation. ${ }^{6}$ Diuretics are usually not required. If recognized early and treated properly, NPPE will resolved rapidly without sequelae.

\section{Conclusion}

This case illustrates that negative intrapulmonary pressure is a crucial factor in producing NPPE. We recommend that direct ETT adapter suctioning be avoided to protect the patient from developing pulmonary complications.

\section{References}

1 Lee KWT, Downs JJ. Pulmonary edema secondary to laryngospasm in children. Anesthesiology 1983; 59: 347-9.

2 Travis $K W$, Todres $I D$, Shannon DC. Pulmonary edema associated with croup and epiglottitis. Pediatrics 1977; 59: 695-8. 
3 Soldano SL, Edwards FH, Place LB, Coben AJ. Postextubation non-cardiogenic pulmonary edema. Mil Med 1993; 158: 278-80.

4 DeSio JM, Bacon DR. Complete airway obstruction caused by a pseudomembranous cast with subsequent negative pressure pulmonary edema. Anesth Analg 1993; 76: 1142-3.

5 Price SL, Hecker BR. Pulmonary oedema following airway obstruction in a patient with Hodgkin's disease. $\mathrm{Br}$ J Anaesth 1987; 59: 518-21.

6 Lang SA, Duncan PG, Shephard DAE, Ha HC. Pulmonary oedema associated with airway obstruction. Can J Anaesth $1990 ; 37: 210-8$.

7 Willms $D$, Shure D. Pulmonary edema due to upper airway obstruction in adults. Chest 1988; 94: 1090-2.

8 Zaloga GP, Prough DS. Fluids and electrolytes. In: Barash PG, Cullen BF, Stoelting RK (Eds.). Clinical Anesthesia, 2nd ed. Philadelphia: J.B. Lippincott Company, 1992: 208.

9 Murphy TM. Spinal epidural and caudal anesthesia. In: Miller RD (Ed.). Anesthesia, 2nd ed. Vol 2. New York: Churchill Livingstone Inc., 1986: 1068.

10 Heimer $L$. The Human Brain and Spinal Cord, 2nd ed. New York: Springer-Verlag Inc., 1995: 400.

11 Janocik SE, Roy TM, Killeen TR. Re-expansion pulmonary edema: a preventable complication. J Ky Med Assoc 1993; 91: 143-6.

12 Pavlin DJ, Nessly ML, Cheney FW. Hemodynamic effects of rapidly evacuating prolonged pneumothorax in rabbits. J Appl Physiol 1987; 62: 477-84.

13 Barin ES, Stevenson IF, Donnelly GL. Pulmonary oedema following acute upper airway obstruction. Anaesth Intensive Care 1986; 14: 54-7. 